\title{
Evaluation of Portable $X$-Ray Fluorescence (XRF) Analyzer for Zirconium-Thickness Measurements
}

\author{
Glenn Moore
}

September 2013

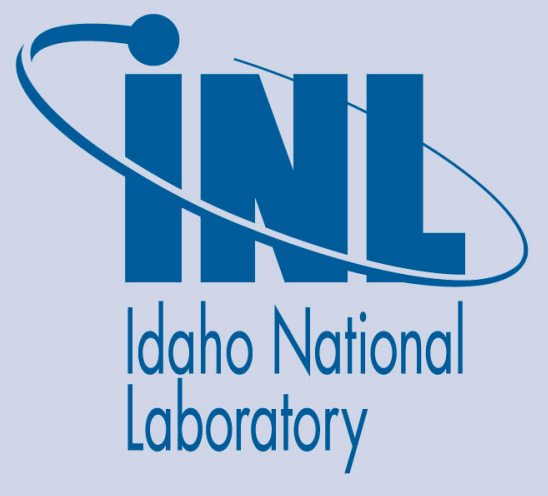

The INL is a U.S. Department of Energy National Laboratory operated by Battelle Energy Alliance 


\section{DISCLAIMER}

This information was prepared as an account of work sponsored by an agency of the U.S. Government. Neither the U.S. Government nor any agency thereof, nor any of their employees, makes any warranty, expressed or implied, or assumes any legal liability or responsibility for the accuracy, completeness, or usefulness, of any information, apparatus, product, or process disclosed, or represents that its use would not infringe privately owned rights. References herein to any specific commercial product, process, or service by trade name, trade mark, manufacturer, or otherwise, does not necessarily constitute or imply its endorsement, recommendation, or favoring by the U.S. Government or any agency thereof. The views and opinions of authors expressed herein do not necessarily state or reflect those of the U.S. Government or any agency thereof. 


\title{
Evaluation of Portable X-Ray Fluorescence (XRF) Analyzer for Zirconium Thickness Measurements
}

\author{
Glenn Moore
}

September 2013

Idaho National Laboratory

Fuel Development Department

Idaho Falls, Idaho 83415

http://www.inl.gov

Prepared for the

U.S. Department of Energy

Office of NNSA

Under DOE Idaho Operations Office

Contract DE-AC07-05ID14517 

Fuel Fabrication \& Characterization Department

\title{
Evaluation of Portable X-Ray Fluorescence (XRF) Analyzer for Zirconium Thickness Measurements
}

\author{
INL/EXT-13-30189 \\ September 2013 \\ eCR 617683
}

Approved by:

See eCR 617683

Glenn Moore

Date 


\begin{abstract}
This Technical Evaluation Report provides details of preliminary testing/experiments performed using a handheld X-ray fluorescence analyzer. The analyzer will be utilized in upcoming fuel-foil-rolling optimization studies at the INL. The studies are being performed in support of DOE's Office of Global Threat Reduction-Reactor Conversion Subprogram. Details of the equipment used, operating parameters, and measurement results are provided in this report.
\end{abstract}




\section{CONTENTS}

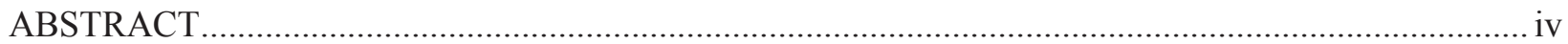

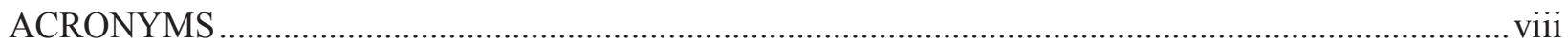

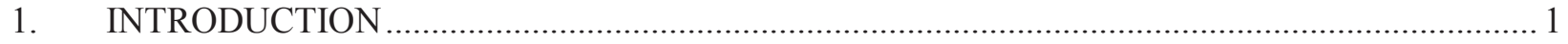

1.1 Equipment and Operating Parameters........................................................................... 1

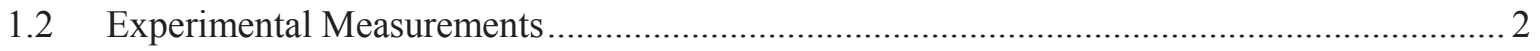

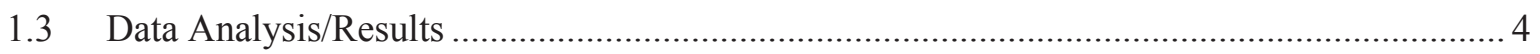

1.4 ZRF-Based Thickness Measurement of Hot- and Cold-Rolled Foils. .................................. 5

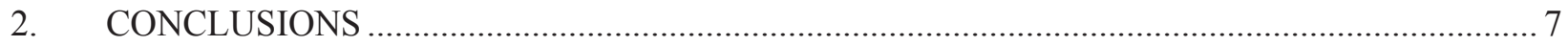

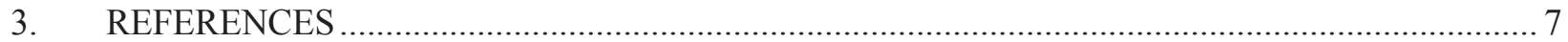

\section{FIGURES}

Figure 1. Olympus DS-2000 Innov-X Delta standard XRF analyzer................................................... 2

Figure 2. Plot of $\mathrm{Zr}$ thickness versus XRF reported $\mathrm{Zr} w \mathrm{t} \%$, $3 \mathrm{~mm}$ aperture in. .................................... 3

Figure 3. Plot of $\mathrm{Zr}$ thickness versus XRF reported $\mathrm{Zr} w \mathrm{t} \%$, $3 \mathrm{~mm}$ aperture out................................... 3

Figure 4. Double exponential function used for calibration curves. ...................................................... 4

Figure 5. Plot comparison of calibration curves; with and without $3 \mathrm{~mm}$ aperture.................................. 4

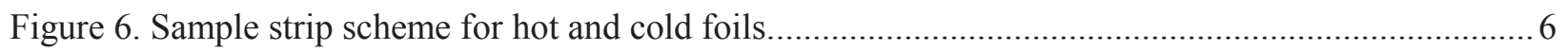

Figure 7. Plots of average Zr thickness: a) Optical-microscopy-based Zr thickness, b) XRF-based $\mathrm{Zr}$ thickness, and c) comparison plot. Error bars represent minimum and maximum

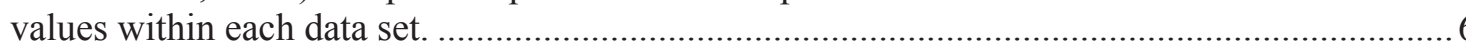

\section{TABLE}

Table 1. Double exponential function coefficients determined via nonlinear regression analysis. 4 


\section{ACRONYMS}

HEU highly enriched uranium

INL Idaho National Laboratory

LEU low-enriched uranium

LANL Los Alamos National Laboratory

SDD silicon-drift detector

TEV Technical Evaluation Report

XRF X-ray fluorescence 


\section{Evaluation of Portable X-Ray Fluorescence (XRF) Analyzer for Zirconium Thickness Measurements \\ 1. INTRODUCTION}

In support of DOEs effort to covert highly enriched uranium (HEU) Research and Test Reactors to Low Enriched Uranium (LEU) based fuel, high density fuel materials are being developed. A monolithic fuel form consisting of a U-10Mo with a zirconium barrier layer is of primary interest. The zirconium barrier layer is established to prevent interdiffusion of the fuel alloy with the aluminum 6061 cladding that is subsequently applied during the fuel-plate-fabrication process. A nominal $\mathrm{Zr}$ thickness of $0.001 \mathrm{in}$. $(0.025 \mathrm{~mm})$ has been determined to be appropriate for the candidate fuel form.

Evaluation, using a handheld XRF analyzer, of the Zr-barrier-layer thickness and uniformity on prepared $\mathrm{Zr}-\mathrm{U}-10 \mathrm{Mo}-\mathrm{Zr}$ co-rolled foils is one component of a rolling optimization study being performed at INL. Within the study, evaluation of hot- and cold-rolling operations associated with fabrication of U$10 \mathrm{Mo}-\mathrm{Zr}$ hot-co-rolled fuel foil, is being performed ${ }^{1}$. Hot rolling is used to bond a zirconium barrier layer to a machined U-10Mo coupon. A carbon-steel rolling assembly is used to contain a lay-up of a U-10Mo foil sandwiched between two $\mathrm{Zr}$ foils during hot rolling. The welded picture-frame assembly serves to prevent oxidation of the "lay-up" and also serves as a radiological-contamination engineering control. Hot rolling is performed using $650^{\circ} \mathrm{C}$ preheated rolling assemblies and a FENN two-high rolling mill configured with 10-in.-diameter rolls. The product of the hot rolling process is $\mathrm{U}-10 \mathrm{Mo} \mathrm{Zr}$ co-rolled foils.

Cold rolling is performed on $\mathrm{U}-10 \mathrm{Mo} \mathrm{Zr}$ co-rolled foil in order to establish the final foil thickness; typically $0.009-0.022$ in. $(0.23-0.56 \mathrm{~mm})$ thick. Cold rolling is performed using a four-high FENN rolling mill configured with $1.625 \mathrm{in} .(41 \mathrm{~mm})$ diameter rolls, the top roll having a $0.0005 \mathrm{in} .(0.013 \mathrm{~mm})$ crown.

It is desirable that the established $\mathrm{Zr}$ barrier layer and fuel core be uniform in thickness. As part of this study, component, nondestructive measurements of $\mathrm{Zr}$ thickness will be obtained using an Olympus Innov-X Delta Standard X-ray fluorescence (XRF) analyzer (DS-2000). Portable XRF analyzers are typically used for metal-alloy verification, lead detection in paint, surveys of ore concentrates, and alloy identification of scrap metal. Use of XRF measurements to determine Zr-barrier-layer thickness has previously been demonstrated by Deborah Suma at Los Alamos National Laboratory (LANL). ${ }^{2}$

\subsection{Equipment and Operating Parameters}

An Olympus DS-2000 Innov-X Delta Standard XRF analyzer with a silicon-drift detector (SDD) and a 4W, $200 \mu \mathrm{A}$ current (max) silver (Ag) X-ray tube was evaluated, Figure 1. The analyzer is configured with a digital camera in the head of the unit, facilitating precise positioning of the unit for measurements. The standard sport size of the unit is approximately $0.16 \mathrm{in}^{2}\left(1 \mathrm{~cm}^{2}\right)$. The unit evaluated was procured with a collimator add-on feature. This feature allows the operator, via the analyzer interface, to insert a $0.12 \mathrm{in.}$ $(3 \mathrm{~mm})$ diameter aperture in front of the SDD detector, thus creating a much smaller survey area of approximately $0.011 \mathrm{in}^{2}\left(0.08 \mathrm{~cm}^{2}\right)$.

The analyzer has a USB interface port that facilitates PC control and data collection. A laptop PC has been configured for used with the analyzer. The PC interface was not used in the initial evaluation, reported here, in order that the operator could become familiar with the use of the analyzer's touch-screen interface. 


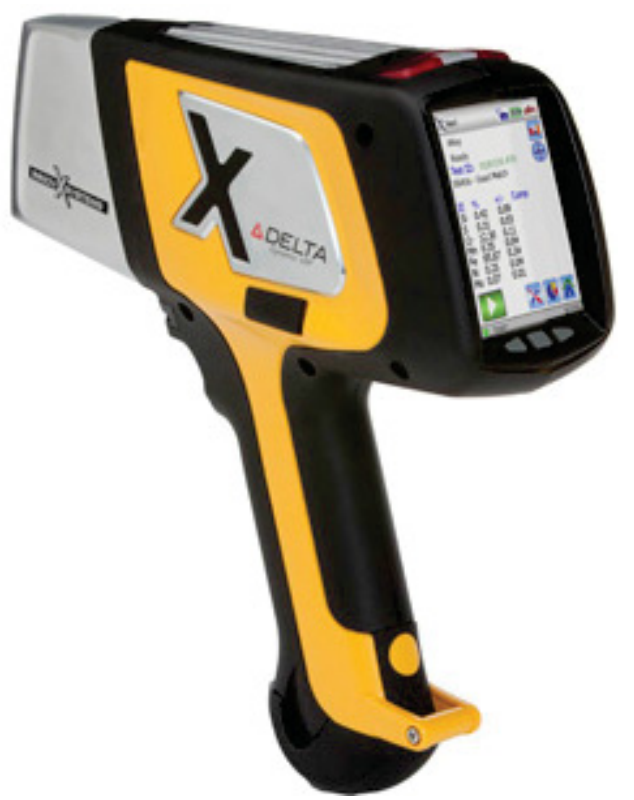

Figure 1. Olympus DS-2000 Innov-X Delta standard XRF analyzer.

\subsection{Experimental Measurements}

The methodology utilized to derived Zr thickness from XRF measurement data involves the use a tab or reference standard. For the experiments performed here, multiple layers of $\mathrm{Zr}$ foil were laminated between acrylic film tape and were placed over an approximately $0.010 \mathrm{in}$. $(0.25 \mathrm{~mm})$ thick U-10Mo foil. Two thicknesses of $\mathrm{Zr}$ foil stock were used: $0.0004 \mathrm{in}$. $(0.01 \mathrm{~mm})$ and $0.001 \mathrm{in} .(0.025 \mathrm{~mm})$. Two reference standards were prepared: 1) six tabs of 0.0004 in. $(0.01 \mathrm{~mm})$ thick foil (Goodfellows, $99.8 \%$ purity Zr, Zr000202/1/, LS395167): 0.0004-0.0024 in. (0.01-0.06 mm) thickness range, and 2) six tabs of 0.001 in. $(0.025 \mathrm{~mm})$. thick foil (Alfa Aesar, $99.8 \%$ purity Zr, Stock No. 38369, Lot No. F26R025): thickness range 0.001-0.006 in. (0.025-0.150 mm).

A nominal 0.010 in. $(1.25 \mathrm{~mm})$ thick bare DU10-Mo foil was used as the substrate for the experiment. The thickness of the DU10-Mo foil was sufficient to prevent detection of the steel table underlying the foil when XRF measurements were being acquired. In order to avoid radiological contamination of the XRF analyzer, the bare U10-Mo foil was maintained inside a polyethylene bag. Measurements were acquired with a known thickness of Zr overlying the DU-10Mo substrate.

Five-second measurements were obtained for each $\mathrm{Zr}$ thickness evaluated; Light element detection mode was not utilized. For each Zr thickness evaluated, two instrument modes were utilized, 1) aperture out, and aperture in. In each mode/configuration, three 5-sec. measurements were obtained for each $\mathrm{Zr}$ tab thickness available. Data were recorded on an activity sheet and then input into an Excel spreadsheet.

The DS-2000 analyzer was set-up/configured to reported measured U and Zr wt $\%$ only. The sum of $\mathrm{U}+\mathrm{Zr}$ would be expected to amount to $100 \%$. However, the actual $\mathrm{U}, \mathrm{Zr}$ wt $\%$ sum range observed was $\sim 93-108 \%$; low sum values were associated with thinner $\mathrm{Zr}$ tab thickness measurements. Sum values greater than $100 \%$ were obtained for $\mathrm{Zr}$ tab thickness of approximately $0.003 \mathrm{in}$. $(0.75 \mathrm{~mm})$ and greater. The source or cause of the observed $\mathrm{U}, \mathrm{Zr}$ wt $\%$ sum variation from $100 \%$ has not yet been established.

A total of ten $\mathrm{Zr}$ tabs were collectively established, six from the $0.0004 \mathrm{in} .(0.01 \mathrm{~mm})$ constructed standard (0.0004-0.0024 in./0.01-0.06 mm) and four from the $0.001 \mathrm{in}$. constructed standard $(0.001-0.004$ in./0.025-0.15 mm), Figure 2 and Figure 3. At 0.005 in. $(0.1027 \mathrm{~mm}) \mathrm{Zr}$ thickness, $100 \% \mathrm{Zr}$ was reported by the XRD analyzer, with and without $3 \mathrm{~mm}$ aperture. 


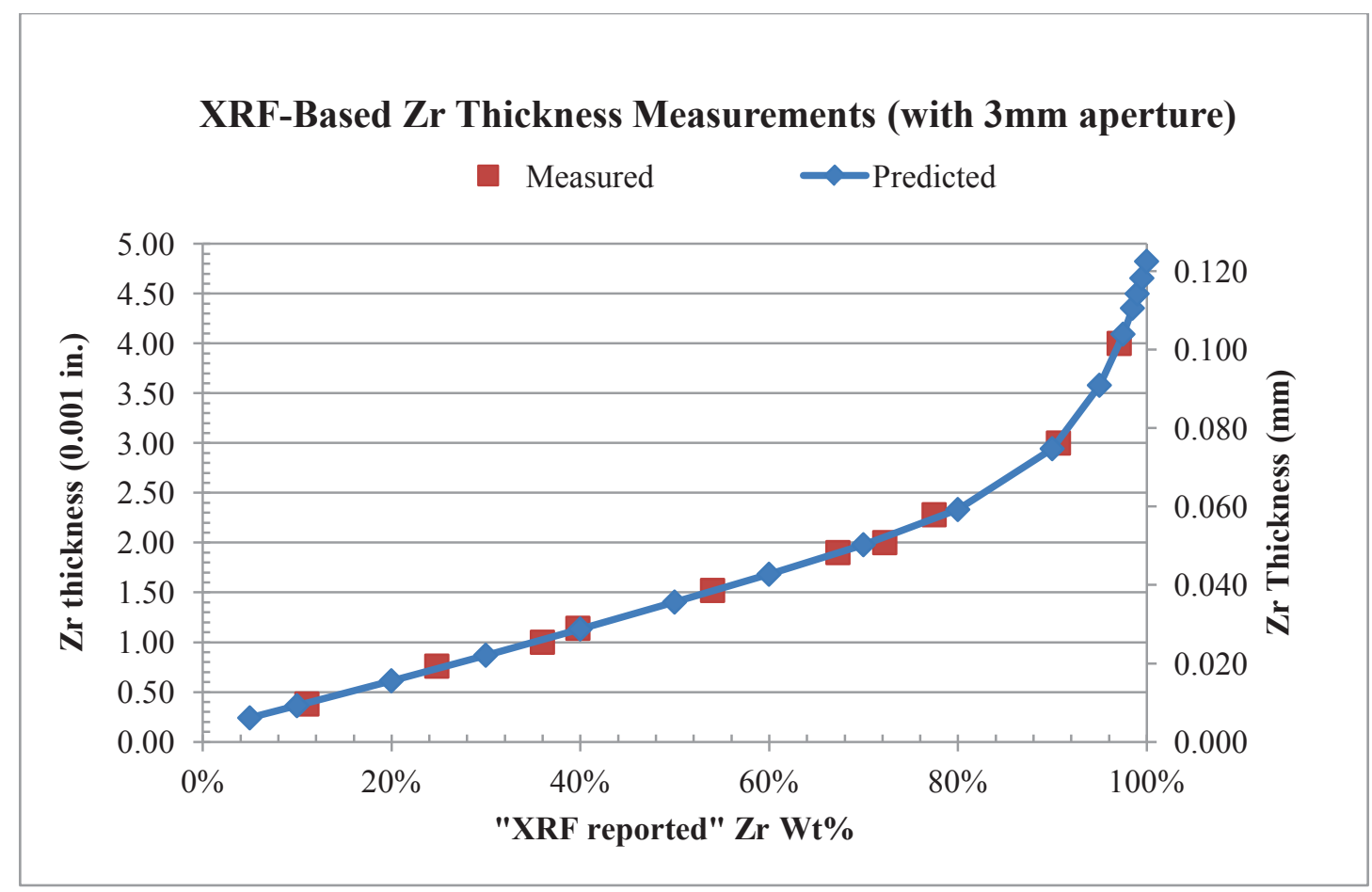

Figure 2. Plot of $\mathrm{Zr}$ thickness versus $\mathrm{XRF}$ reported $\mathrm{Zr}$ wt\%, $3 \mathrm{~mm}$ aperture in.

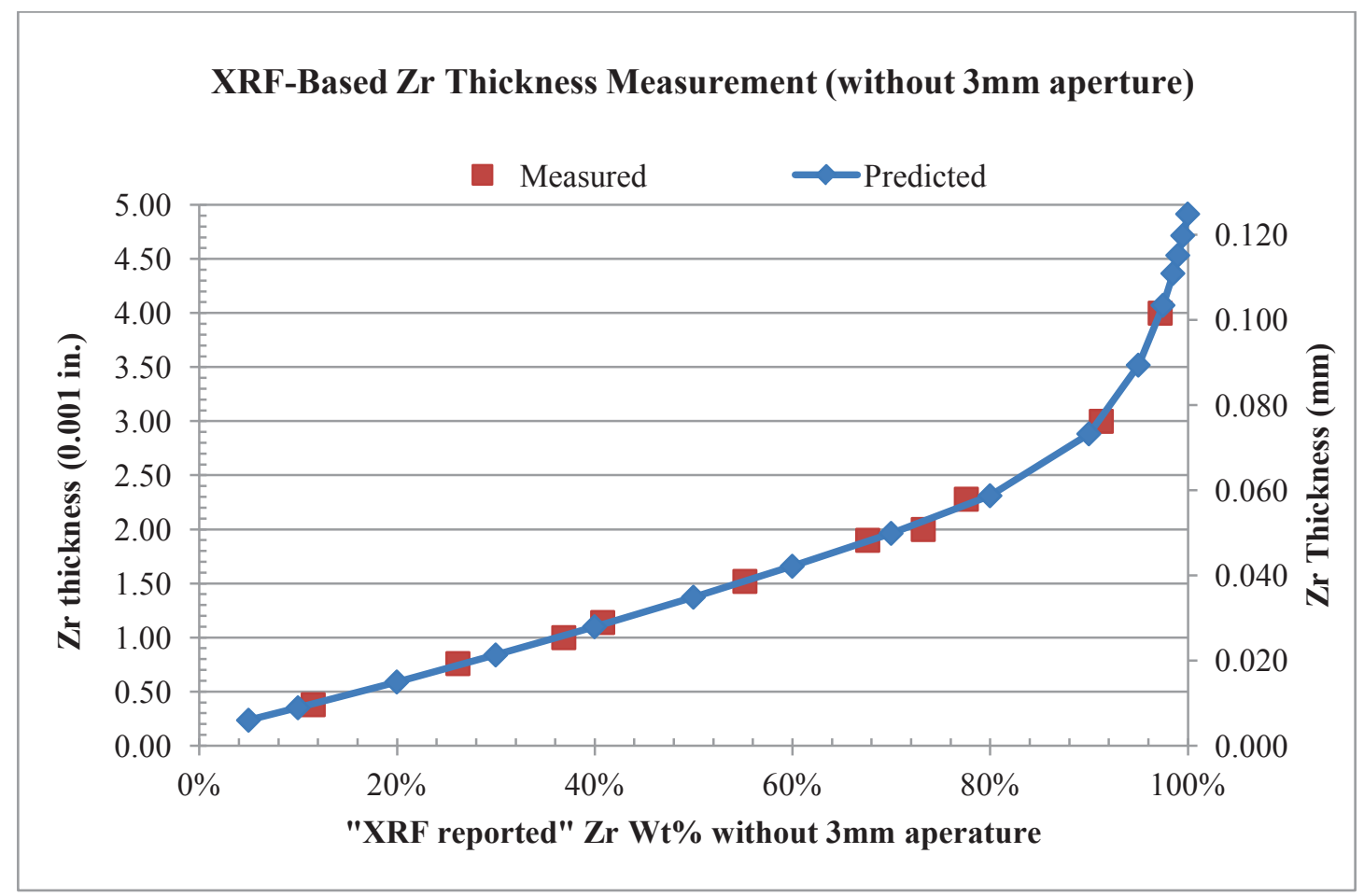

Figure 3. Plot of $\mathrm{Zr}$ thickness versus $\mathrm{XRF}$ reported $\mathrm{Zr}$ wt $\%, 3 \mathrm{~mm}$ aperture out. 


\subsection{Data Analysis/Results}

The relationship between $\mathrm{Zr}$ tab thickness and the $\mathrm{wt} \% \mathrm{Zr}$ reported by the XRF analyzer was predicted using nonlinear regression analysis; ten point XRF data sets, "Measured" shown in Figure 2 and Figure 3 were used as input. Coefficient values were determined for a double exponential function, Figure 4, using an Excel add-in module developed by Leonardo Volpi, Foxes Team. Namely, OPTIMIZ, Ver 2.0.1, 2006; nonlinear regression using five parameter exponential function employed here. Validation of the trendline was accomplished using a graphical overlay "Predicted" trendline; shown in Figure 2 and Figure 3.

The " $\mathrm{x}$ " input values for the nonlinear analysis performed was $100-\mathrm{Zr} w \mathrm{t} \%$.. The trendline function coefficients and $\chi^{2}$ value are provided in Table 1. Trendline comparison, with and without $3 \mathrm{~mm}$ aperture, is shown in Figure 5.

$$
Z r_{t h}(x)=a_{0}+a_{1} * e^{k_{1} * x}+a_{2} * e^{k_{2} * x}
$$

Where: $\mathbf{x}=100-\mathrm{XRF}$ reported $\mathrm{Zr} \%$

And $\boldsymbol{Z} \boldsymbol{r}_{\boldsymbol{t h}}=$ predicted $\mathrm{Zr}$ tab thickness in mils (0.001 in.)

Figure 4. Double exponential function used for calibration curves.

Table 1. Double exponential function coefficients determined via nonlinear regression analysis.

\begin{tabular}{|l|c|c|c|c|c|c|}
\hline & \multicolumn{7}{|c|}{ Double Exponential Function Coefficients } \\
\hline Data Set & $a_{0}$ & $a_{1}$ & $k_{1}$ & $a_{2}$ & $k_{2}$ & $\chi^{2}$ \\
\hline With $3 \mathrm{~mm}$ aperture & -9.220 & 12.082 & -0.257 & 1.962 & -16.198 & 0.0042 \\
\hline Without $3 \mathrm{~mm}$ aperture & -4.839 & 7.778 & -0.449 & 1.978 & -19.302 & 0.0052 \\
\hline
\end{tabular}

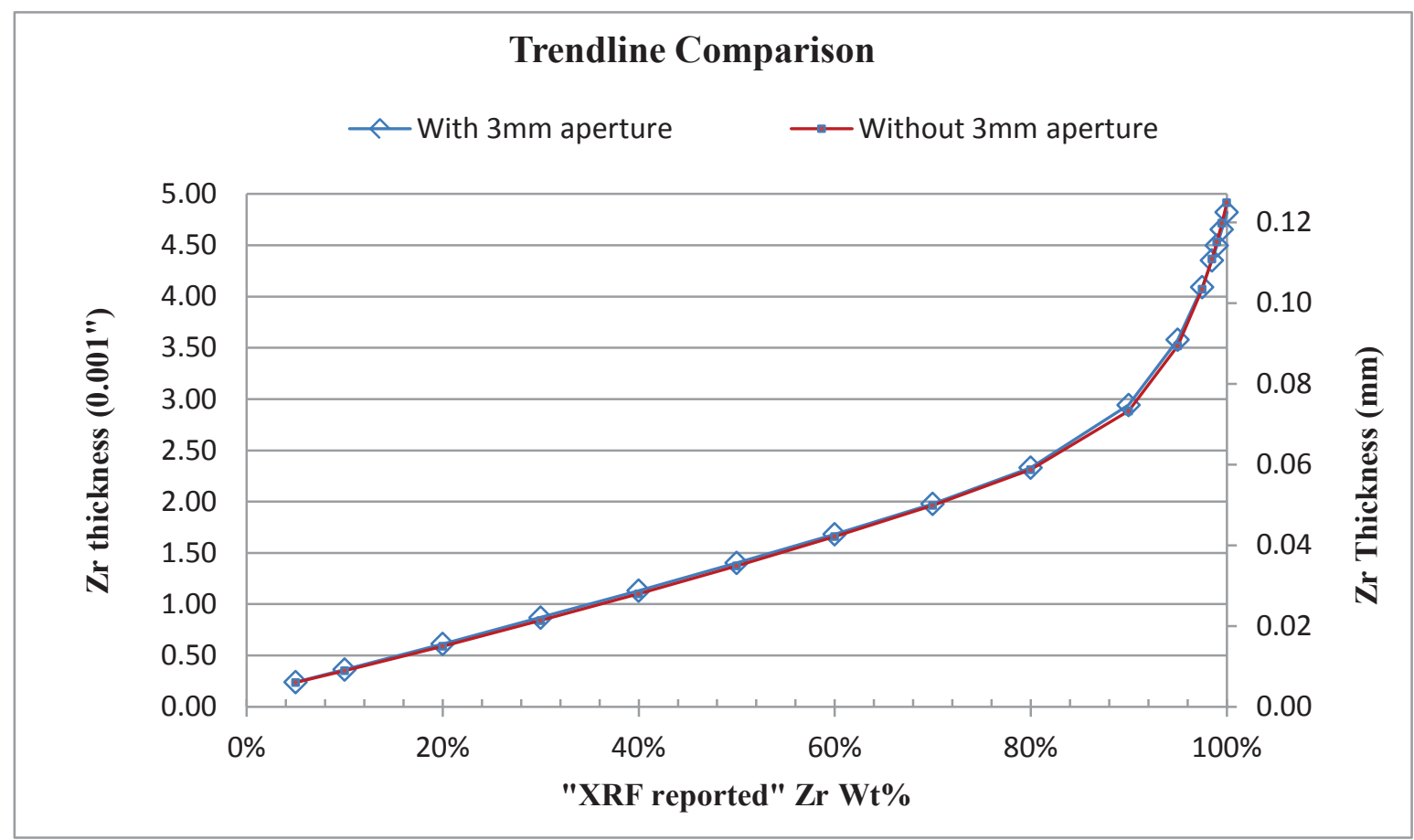

Figure 5. Plot comparison of calibration curves; with and without $3 \mathrm{~mm}$ aperture. 
Trendline coefficient determinations were made using 3-point averaged data as input. Subsequently, the minimum and maximum XRF reported $\mathrm{Zr}$ wt $\%$ data was used to predict $\mathrm{Zr}$ tab thickness. The results indicate that the trendline equation predicts the actual tab thickness within $\pm 2 \%$. No significant difference was observed between data collected with or without the $3 \mathrm{~mm}$ aperture in position, as would be expected given the thickness uniformity of the $\mathrm{Zr}$ foil-stock used in the evaluation.

For the Zr thickness range of 0.0004-0.002 in. (0.01-0.051 mm), a near linear correlation with $\mathrm{Zr}$ $\mathrm{Wt} \%$ is observed in Figure 5. The use of linear trendlines/equations for samples having $\mathrm{Zr}$ thickness in this range will be evaluated.

\subsection{ZRF-Based Thickness Measurement of Hot- and Cold-Rolled Foils.}

Initial evaluation of the Olympus DS-2000 handheld XRF analyzer was performed using the two tab standards prepared and Zr co-rolled DU-10Mo hot- and cold-rolled foils. Hot- and cold-rolled foils were fabricated at the INL using DU-10Mo alloy coupons prepared at LANL, size: $1.2 \mathrm{in}$. W $\times 2.0 \mathrm{in}$. L $\times 0.14$ in $(30 \mathrm{~mm} \mathrm{~W} \times 51 \mathrm{~mm} \mathrm{~L} \times 3.5 \mathrm{~mm} \mathrm{~T})$. The starting thickness of the zirconium foil used was $0.010 \mathrm{in}$. $(0.25 \mathrm{~mm})$. Eight hot rolled foils, $0.036-0.040 \mathrm{in} .(0.91-1.02 \mathrm{~mm})$ thick were fabricated; the respective $\mathrm{Zr}$ thickness established was $0.0023-0.0025$ in. (0.057-0.064 mm). Subsequently, the foils were cold-rolled to a final nominal thickness of 0.015 in. $(0.38 \mathrm{~mm})$; nominal $\mathrm{Zr}$ thickness was $0.00094 \mathrm{in} .(0.024 \mathrm{~mm})$.

Sample strips were taken from hot- and cold-rolled foils, as shown in Figure 6. XRF-based Zrthickness measurements, with $3 \mathrm{~mm}$ aperture in, were taken at 14 points on the front side and back side of each foil sample strip. Given that the Zr thickness range being evaluated was $\sim 0.0005-0.0001$ in. (0.013$1.025 \mathrm{~mm})$ for cold rolled foils and $0.0013-0.002 \mathrm{in} .(0.033-0.051 \mathrm{~mm})$ for hot-rolled foils, a linear trendline-fit equation was utilized for $\mathrm{Zr}$ thickness calculations. Data used to generate trendline equations were obtained via pre-session measurements of five tabs associated with the 0.0004 in.-based $\mathrm{Zr}$ tab standard, nominally $0.0004-0.002$ in. $(0.01-0.05 \mathrm{~mm})$.

Subsequently, longitudinal and transverse samples were extracted, mounted, and polished for metallurgical evaluation. Prior to mounting, a high-speed saw cut each foil piece in order to remove any shearing deformation; thus, the center of XRF measurement regions approximately coincided with the polished sample face.

During optical microscopy evaluation of samples, a series of Zr-thickness measurements were obtained. Specifically, for hot-rolled foil samples, $25 \mathrm{Zr}$-thickness measurements on the front and back side of each sample piece were made, 100 data points per longitudinal and transverse met mount (60 used for data comparison to be consistent with cold-rolling data sets). For cold-rolled foils, $15 \mathrm{Zr}$ thickness measurements on the front and back side of each sample were made, 60 data points per longitudinal and transverse sample.

For comparison, the applicable subset of XRF-based Zr-thickness measurement data was compiled. Specifically, four data points were measured for each sample piece face, corresponding to 16 data points per longitudinal and transverse met mount sample, Figure 7.

From the plots shown in Figure 7, it can be seen that the thickness variability (minimum to maximum range) within XRF data sets was significantly less than that for optical-based thickness measurements. This is attributed to the $3 \mathrm{~mm}$ aperture sampling area of the XRF device as compared to the point-based optical microscopy measurements. It is also observed that, on average, the XRF-based Zr-thickness measurements are $20-25 \%$ less than the corresponding optical-based measurements. This discrepancy is currently under investigation. The optical microscope's "length measurement tool," associated with the Zeiss image analysis software, was verified using a micrometer scale standard and found to be accurate. 


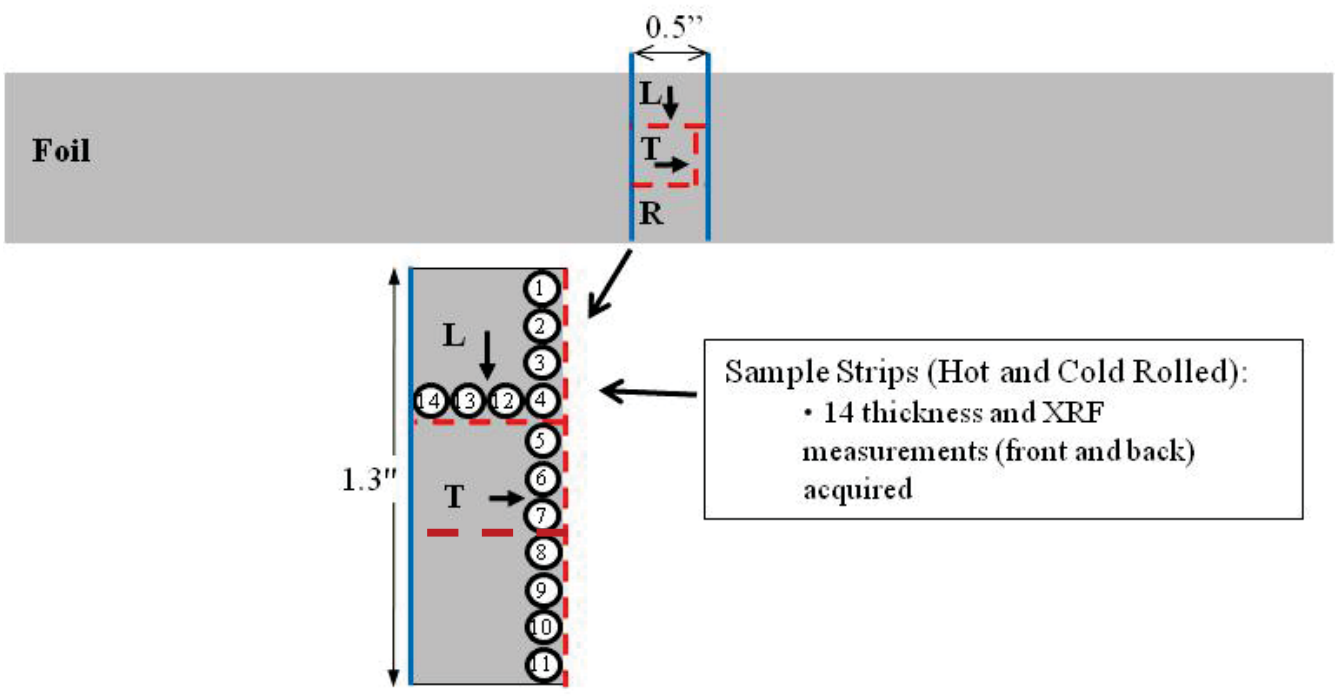

Figure 6. Sample strip scheme for hot and cold foils.

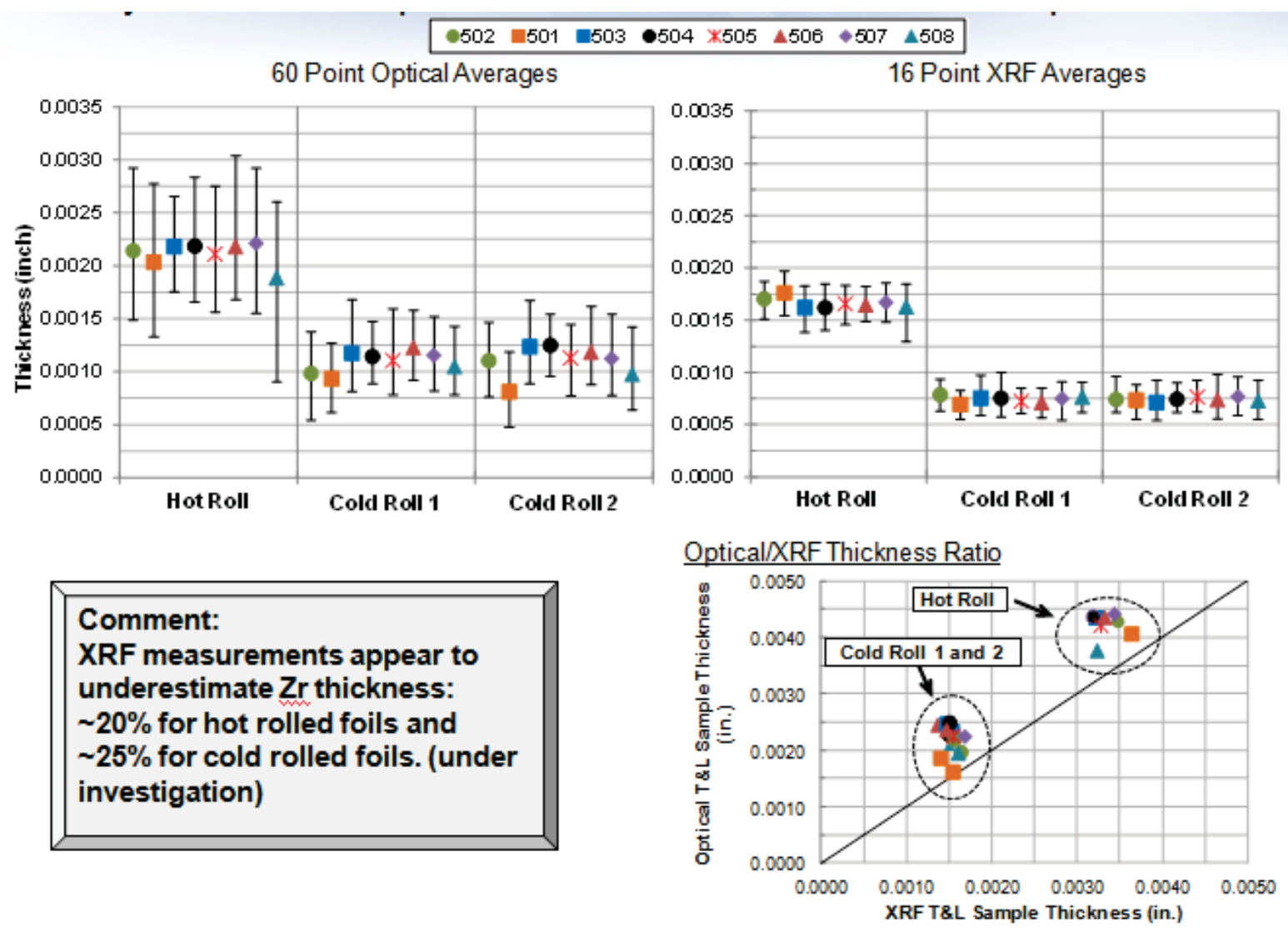

Figure 7. Plots of average Zr thickness: a) Optical-microscopy-based Zr thickness, b) XRF-based Zr thickness, and c) comparison plot. Error bars represent minimum and maximum values within each data set. 


\section{CONCLUSIONS}

Five second-data acquisition surveys using Olympus DS-2000 handheld XRF analyzer can effectively be used to determine $\mathrm{Zr}$ barrier layer tab thickness in conjunction with a DU-10Mo substrate.

A Zr thickness range of $0.0004-0.0040$ in. $(0.01-0.10 \mathrm{~mm})$ was demonstrated in this evaluation. The data indicate that a Zr-thickness range of approximately $0.0001-0.0045 \mathrm{in} .(0.01-0.114 \mathrm{~mm})$ is measurable by the DS-2200 XFR analyzer unit.

Five one-thousandths of an inch $(0.127 \mathrm{~mm})$ thick $\mathrm{Zr}$ exceeds the DS-2000 X-ray penetration and signal return; i.e., no U-substrate detection was observed when using 0.005 in. (0.127 mm) Zr.

The double logarithmic function was found to be suitable for establishing trendlines and calibration curves for the intended purpose of predicting Zr-barrier-layer thickness. Approximately $2 \%$ measurement variability was observed in the 3-point data sets collected.

There does not appear to be any significant difference between data collected with $3 \mathrm{~mm}$ aperture in or with $3 \mathrm{~mm}$ aperture out.

A simple XRF measurement scheme, one that surveys for only $U$ and $\mathrm{Zr}$, has been shown to be effective for the prediction of $\mathrm{Zr}$ thickness overlying a U-10Mo substrate.

Initial results of determining Zr thickness using the DS-2000 handheld XRF analyzer was performed. Results indicate that the $\mathrm{Zr}$ thickness in actual foils is under predicted by, on average, $20-25 \%$ relative to optical-microscopy-based measurements; this discrepancy is currently under investigation.

\section{REFERENCES}

[1.] Moore, Glenn A. and M. Craig Marshall, "Co-Rolled U10Mo/Zirconium-Barrier-Layer Monolithic Fuel Foil Fabrication Process,” INL/EXT-10-17774 (2012).

[2.] Summa, Deborah A. "Intelligent Integrated Machining: Handheld XRF for Mapping Zr Coating and Al-6061 Cladding Thickness in RERTR-Fuel Elements,” Los Alamos National Laboratory Report LA-UR-12-26820. 